\title{
Do it Right: Appropriate Ways for Teachers to Treat and React to Aggressive Children in Jordanian Kindergartens
}

\author{
Ebtesam Q. Rababah* \\ Majedah F. Abu Alrub \\ Yarmouk University, Jordan
}

\author{
Received: 25/11/2017 Accepted: 16/4/2018
}

\begin{abstract}
This study explored the types and causes of aggression and the ways teachers treat and react to aggressive children in Jordanian kindergartens in the Irbid district. The sample consisted of the first 20 teachers who responded to the letter of participation sent to them. Data on the causes and types of aggression and prevention strategies were collected by descriptive qualitative design, with semi-structured open-ended interviews, as well as observation of Jordanian kindergarten teachers. The results of the study revealed three themes: factors that shape aggression, sanctions rather than punishment and social learning and culture. Also, the results indicated that social learning through positive modelling was mostly needed to help aggressive and disruptive students and change their behaviour. In light of the results, further research utilizing quantitative and qualitative research methods to achieve broader understanding of aggression in pre-school settings is recommended.
\end{abstract}

Keywords: Aggressive behavior, kindergarten, social learning theory, Jordan.

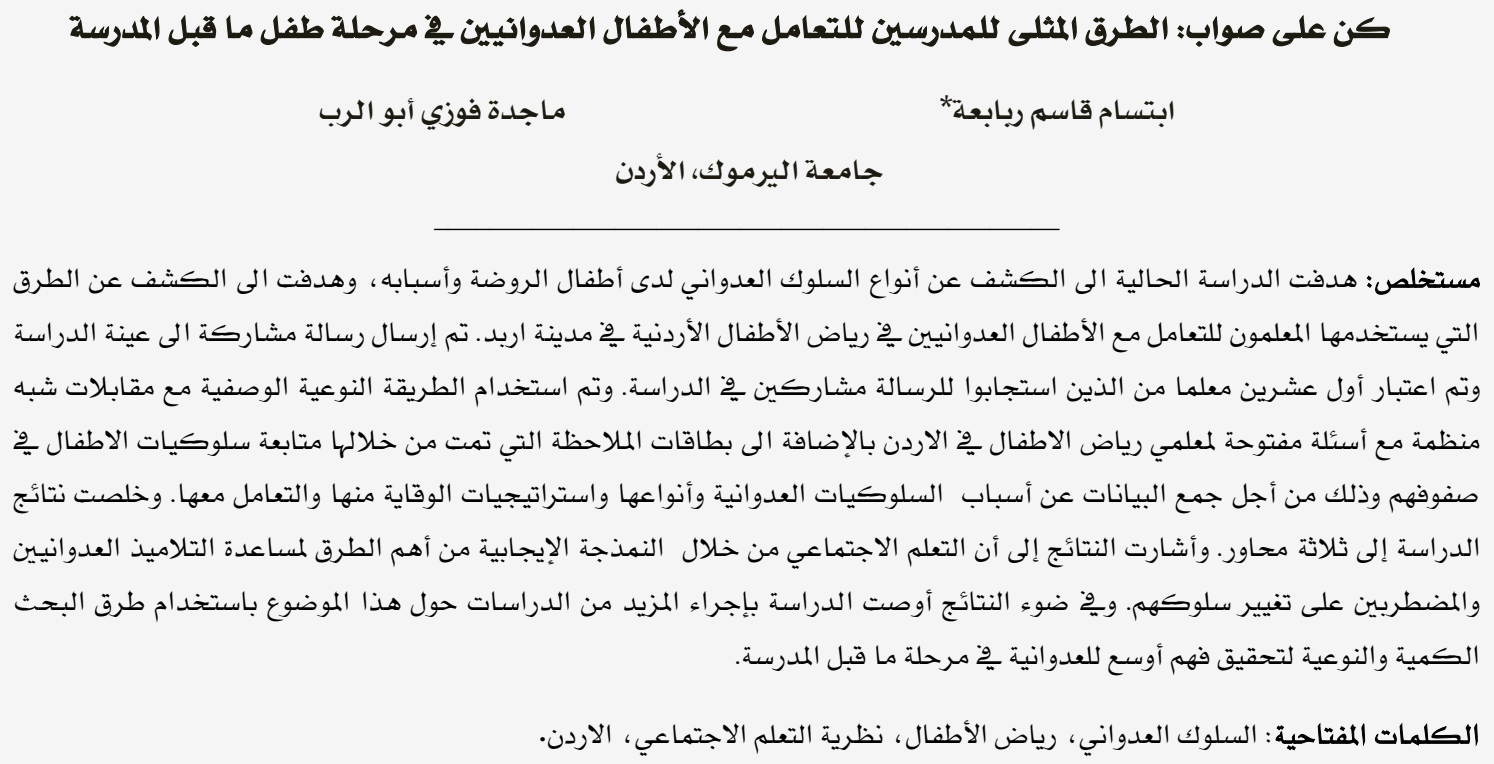

*ebtesam.r@yu.edu.jo 
Many teachers observe that a few of their students often antagonize others (Al Saleh, 2012; Al-Sarayreh, 2009). Some students get involved in fights with other students, which can make the teacher's mission in the classroom difficult (Aldridge \& Goldman, 2007; Shechtman \& Ifargan, 2009). Aggressive behavior in the classroom is easy to identify, but difficult to ignore. Aggression is particularly important to address at the pre-school level because how it is addressed can affect physical, cognitive, and social consequences of a person who could grow more violent in the future. Also, aggression in preschool affects peers, teachers, and the whole learning and teaching processes. Overall, aggression is commonly believed to be an important personality problem faced by teachers (Arbeau \& Coplan, 2007; Al-Sarayreh, 2009), parents and society in general. Preschool is a sensitive period for learning how to reduce aggression. Since treatment of aggression becomes increasingly difficult as children grow older, it seems potentially more effective to focus treatment and prevention efforts during early and preschool years (Doumen, Verschueren, \& Buyse, 2009; Sakimura, Dang, Ballard, \& Hansen, 2008). Childhood aggression has been studied extensively and in varied ways. Much current research is focused on aggression at home, schools, and adolescent violence (Al Saleh, 2012; Al-Sarayreh, 2009; Shechtman \& Ifargan, 2009). A number of previous studies have also examined causes of aggression in preschool (Daly \& Perez, 2009; Doumen, Verschueren, Buyse, \& Germeijs, 2009; Posada \& Pratt, 2008; Sakimura et al., 2008; Thornberg, 2006). For example, Sakimura et al. (2008) investigated the co-occurrence of cognitive problems and difficult temperament characteristics in children with aggressive behavior.

Previous studies have found multiple reasons for children to use physical aggression. One common reason stems from being unable to process strong emotions such as anger (Center of Excellence for Early Childhood Development, 2008). Other reasons include the rejection of the child from others, and a lack of encouragement (Doumen et al., 2009; Thornberg, 2006). For some children, the tendency toward physical aggression and other difficult behavior appears to be innate. This is backed by some research that has linked the use of tobacco, alcohol, and drugs during pregnancy im- pacting the ability of the child's brain to control aggressive behavior (Center of Excellence for Early Childhood Development, 2008).

\section{Form and Function of Aggression}

Two types of aggression are commonly discussed in the literature: physical and relational. More research is focused on physical aggression than on relational. This raises the question of whether both types of aggression are emerging in preschools. Several relevant studies have addressed the question. For example, McEvoy, Estren, Rodriguez, and Olson (2003) assessed relational and physical aggression in preschool children by comparing results from three different methods (teacher rating scales, peer nomination, and direct observation). The results from descriptive statistics showed that all three methods found both types of aggression in preschool, and that girls had the highest rate of relational aggression while boys had higher rates of physical aggression.

Ostrov and Crick (2007) investigated the problem of aggression (forms and functions) in early childhood. The purpose of their longitudinal study was to examine if relational aggression had utility in the prediction of adjustment problems (peer rejection and student teacher conflict) above and beyond functions of physical aggression. Ostrov and Crick (2007) tested the hypothesis that relational aggression functions types will predict future social-psychological adjustment problems and beyond the role of physical aggression. The study results showed that boys were more physically aggressive than girls, while the girls were more relationally aggressive than boys. Moreover, results showed that proactive and reactive relational aggression predicted student-teacher conflict above and beyond the role of reactive physical aggression (Ostrov \& Crick, 2007).

Another study addressed the problem of relational, physical aggression, and deception as an important risk factor for negative outcomes (Ostrov, Ries, Stauffacher, Godleski, \& Mullins, 2008). Ostrov et al. (2008) stated two main purposes for their study. The first purpose was to examine the relationships between observed relational and physical aggression and the reported deception by the teacher. The second purpose was to compare the observa- 
tional methods for the types of aggression with teacher reports of aggression and predicting of deceptive behavior. The researchers hypothesized that observation methods would be a good predictor of deceptive behavior "above and behind" teacher report methods. The researchers found that relational and physical aggression were associated with high prediction of deceptive behavior. Furthermore, observation methods and teacher reports led to the same aggression construct. Therefore, this study supports that observation and teacher reports are good methods to assess types of aggression in preschools (Ostrov et al., 2007).

A different relevant study looked at the development of physical aggression in early childhood (Tremblay et al., 2004). The purpose of their study was to investigate the trajectories of physical aggression. The researchers put the children of the study into three groups based on aggression levels. They found that $28 \%$ of the sample had little or no physical aggression, $58 \%$ of children had modest aggression, and around $14 \%$ of children in the sample had high physical aggression. Similar to a number of studies in the literature, males were found to have a higher rate in physical aggression than females.

\section{Why Do Children Become Aggressive?}

The development of childhood aggression has been associated with multiple factors, such as modeling of aggressive behavior from TV, movies, and games, poor parent practice, family conflict and maltreatment, harsh physical punishment, parental disharmony, peer conflict, and teacher conflict, among others. Daly and Perez (2009) addressed the problem that media violence increased aggression probabilities. The researchers specified primary and secondary purposes, which were to examine the relationship between media violence and aggressive behavior in preschool children and to evaluate multiple variables that influence children's behavior. Their major results were that poor self-regulation was significantly associated with aggressive behavior, boys were three times more aggressive than girls, and increased viewing of media violence was associated with higher overall aggression (Daly \& Perez, 2009).

Additionally, researchers have had mixed results around the concept that children are born to be either aggressive or even-tempered. Based on Shaffer (2009), children are born with four different temperaments. Forty percent of children are considered as easy or flexible. Fifteen percent of children are slow to warm up or cautious. Ten percent of children are difficult, active, or feisty often fussy, irregular in sleeping, fearful of new people and situations, easily upset by noise and commotion, high strung and intense in their reaction. The rest of the children tend to be miscellaneous.

A study by Sakimura et al. (2008) examined the problem of aggressive behavior in three to five year old children and their cognitive abilities and temperament. They further examined if the children's aggressive behavior could be connected with their temperament and cognitive ability. The researchers hypothesized that aggressive children have a difficult temperament and low cognitive ability. They made two major findings. First, teachers rated children as more aggressive than did parents. Second, they found three groups of aggressive children according to their temperament and cognitive ability, which were labeled as "difficult temperament-borderline cognitive," "difficult temperament-average cognitive," and "midrange temperament-average cognitive." These results suggest that children who are born with difficult temperaments have a tendency to be aggressive, regardless of cognitive ability (Sakimura et al., 2008).

Peer conflict was another frequently found cause of childhood aggression. Thornberg (2006) conducted a study to examine preschool children's conflict strategies. The purpose of the study was to examine seven peer conflict strategies in preschool children. The major finding was that preschool children reacted with physically aggressive behavior when the opponent used physical aggression. This result indicates children perpetuate aggressive behaviors by acting out in the same ways and furthering the cycle rather than ending it by responding in non-aggressive ways (Thornberg, 2006).

Another study examined relationships between family maltreatment and aggressive behavior in children (Cullerton-Sen et al., 2008). The main purpose of their study was to examine the association between maltreatment and aggressive behavior and gender differences. They found that maltreatment was a good predictor of physical aggression, boys 
were more physically aggressive than girls, and gender and maltreatment were good predictors of relational aggression (Cullerton-Sen et al., 2008).

In addition to effects of the relationships between child and parent on behavior, many researchers have focused on the effect of the relationship between teachers and children on behavior. Doumen, Verschueren, Buyse, Germeijs, and Luyckx (2008) conducted a study within one school year to investigate the effect of interaction of teacher-child conflict and aggressive behavior. The researchers sought to examine the "bidirectional model" of the reciprocal nature of conflict between teacher and children and aggressive behavior. They attempted to answer the question of whether the reciprocal teacher-child conflicts affected the children and increased aggressive behavior. The results showed low levels of teacher conflict and child aggression reported by the teachers. However, they did find statistically significant results indicating a change for child conflict and increased aggressive behavior. These results suggest that aggressive behavior and teacher-child conflict could have reciprocal influences over time. Thus, positive and encouraging teacher-student relationships can ensure the success of a student (Geng, 2011).

\section{Aggression Prevention and Intervention}

Prevention and treatment of aggression is vitally important, especially in early childhood years. Much research has been conducted searching for appropriate ways for pre-school teachers to treat and react to aggressive children. For example, Brotman et al. (2008) studied the effects of prevention of physical aggression in preschool. The study examined the long-term effects of the Incredible Years Series (IYS) program on physical aggression in preschool children, parent practice, and child social competence. Ninety-two at risk preschoolers with delinquent biological siblings in New York City comprised the sample. The study's major results included a decrease in observed physical aggression in the intervention group that went through the IYS program. Also, parent ratings had no effect on results of the intervention program on physical aggression, and aggression was nine times lower in the intervention group. These results suggest that effects over time can be found for intervention programs in reducing physical aggression behavior in at risk children.

Waliski and Carlson (2008) addressed the problem of low self-esteem and aggressive behavior. The research problem was concerned with the importance of interventions for preventing aggressive behavior. The study attempted to identify appropriate intervention work to improve children's behavior. The research sought the effect of interventions on children's emotional awareness and behaviors. The sample had fifteen children at ages four and five from a local public school district. The authors used a child behavior checklist reported by the teacher to measure child behavior to collect quantitative data, in addition to an emotional awareness measure. The major results found an increase in children's emotional awareness, and more positive behavior in post intervention compared with pre intervention. These results suggest that the interventions should focus in developing early social and emotional awareness to decrease aggressive behavior.

Another experimental study examined an intervention for physical and relational aggression (Ostrov et al., 2009). The purpose of the study was to develop and assess the effects of a "preliminary version of a classroom" preventive intervention in physical and relational aggression. The suggested intervention program was found to have statistically significant effects on aggression. These results suggest that intervention programs can decrease physical and relational aggression and increase prosocial behavior in kindergarten children (Ostrov et al., 2009).

Shechtman and Ifargan (2009) addressed the problem of integrated and segregated interventions and aggression. The purpose of their study was to compare these two types of interventions in reducing aggressive behavior. In this case, "integrated" meant an intervention class, and "segregated" consisted of a counseling intervention. They employed four instruments to collect the quantitative data: a peer nomination instrument to measure levels of child aggression, a teacher report form to measure adjustment symptoms, the Illinois aggression scale to measure classroom variables, and a classroom environment scale to measure class relations. The researchers found that both interventions were better than a con- 
trol in reducing aggressive behavior, but did not find statistically significant differences between the two experimental groups. This study implies that either integrated or segregated interventions are more effective than doing nothing in reducing aggressive behavior; though based on this study, one may not be better than the other (Shechtman \& Ifargan, 2009).

Manning and Bear (2002) addressed the problem of moral reasoning and its influence on the treatment of aggression. Their study examined specific types of moral reasoning (types of hedonistic reasoning and types of needsoriented reasoning) and their relationship to teacher-reported aggressive behavior. The authors wanted to learn if children were concerned about punishment related to their aggression. The study sample consisted of 203 students in 16 classrooms (5 first-grade, 11 second-grade) from two elementary schools in a Mid-Atlantic region of the U.S. Individual interviews were conducted to assess students' verbal ability and moral reasoning. The teacher completed measurements of overt aggression for each student. Interview results indicated that low verbal skills and moral reasoning was connected to higher aggression. Results showed that adding a moral reasoning component might enhance the effectiveness of aggression prevention and intervention programs (Manning \& Bear, 2002).

Family dynamics and classroom aggression has also been explored. For example, Dykeman (2003) addressed family conflict resolution and child behavior in the classroom. The study examined the effect of an intervention program in reducing difficult behavior in the classroom and reducing family conflict. The intervention program focused on family conflict resolution. The major result showed an improvement in classroom behavior resulting from decreased verbal aggression and increased use of reasoning. However, the intervention did not have a statistically significant effect on physical aggression (Dykeman, 2003).

Teachers' responsivity and reactions to children are important in how their behavior develops. Arbeau and Coplan (2007) researched teachers' beliefs and responses to children with difficult behaviors such as being shy, aggressive, or asocial. They investigated whether teachers' attitudes and responses were different according to different children and their behaviors. Their hypotheses were that teachers would have negative attitudes with aggressive children and positive attitudes with prosocial children. They also expected teachers to attribute aggressive and shy behaviors to external causes, and prosocial behaviors to internal causes. The results did indeed statistically support that teachers have different attitudes and responses toward children based on their behavior types.

McComas, Johnson, and Symons (2005) analyzed the interaction between children with aggressive behavior and their teachers and peers. The study had twelve preschool children in a public childcare center as the sample. Researchers conducted twenty minutes of weekly direct observation during free play time for seven months. The study found that peers and teachers do in fact respond differently to children with aggressive behavior than non-aggressive children. This suggests that aggressive behavior in preschoolers does affect social interactions between teachers and children in a negative way.

In conclusion, the literature on aggression and children, including early childhood, is vast. However, some commonalities have emerged. The two main types of aggression emerging in preschool are known as relational and physical aggression. Boys are frequently found to be more physically aggressive, while girls are more relationally aggressive (McEvoy et al., 2003; Ostrov \& Crick, 2007). Children's aggressive behaviors were found to come from multiple causes, including violence in the media (Daly \& Perez, 2009), peer conflict (Thornberg, 2006), and temperament (Sakimura et al., 2008). Another important finding was that prevention and intervention strategies of varying types were effective in reducing aggressive behavior to different extents. It is also important to note that almost any intervention was found to be more effective than no intervention.

\section{Research Problem and Questions}

Aggression in pre-school has not been studied from a cultural viewpoint. From the researchers' observations as educational supervisors in Jordanian kindergartens and elementary schools for more than fifteen years, there is an apparent increase in aggressive behavior, even violent behavior, among the youngest students in Jordanian preschools. Much of the 
current research in Jordan is focused on aggression in secondary schools (Al-Sarayreh, 2009). Meanwhile, little attention has been given to aggression in Jordanian pre-schools, and how it can be prevented. More attention is warranted at the pre-school level to understand why the increase of aggression is occurring and how to handle it. This knowledge could also inform studies on older children by better understanding them from a younger age.

Increased knowledge will also help guide school administrators when they make important decisions regarding adjusting responsibilities for teachers to better prevent aggression in pre-schools. This awareness would also encourage administrators and teachers to seek aggression-reduction, treatment and prevention programs designed to help teachers be more effective with aggressive children in classrooms.

This study explored the ways that teachers treat and react to aggressive children in Jordanian kindergartens by answering the following questions:

1. Why do children become aggressive?

2. What are the types of aggression that emerge in Jordanian kindergartens?

3. How do pre-school teachers handle aggressive behavior in Jordanian kindergartens?

A study of this kind is significant because while it is an important topic, no empirical studies were found that directly addressed aggressive children in Jordanian kindergartens. Most of the available studies in Jordan have evaluated aggressive behavior at the high school level. If educators in Jordan want to understand and correct the problem of aggression in schools, further exploration is warranted to test differences of aggression for each school level. Furthermore, if this problem can be addressed at early ages, then it could likely impact the problem at older levels as well.

\section{Theoretical Framework}

This study followed the social-cognition theory of Bandura (1977). This theory was called social learning until the mid-1980s. Bandura saw that human development is a process of interaction between the child as a psychobiological organism and the child's socio-physical environment. Social learning is a method of teaching pro-social behavior through observation and modeling others' behaviors (Bandura, 1977). Thomas (2005) summarized this idea by stating:

Children are most likely to model their own behavior after the actions of people who are of their own gender, age, ethnic background, and social status rather than the actions of people they see as being different from themselves; are regarded as successful and prestigious; and receive rewards, such as money, fame, or high socioeconomic status, rather than being punished for their behavior. (p. 155).

Bandura stated that positive social and observational learning through modeling could modify disruptive behaviors in students while also helping with the self-efficacy or confidence of the teachers. Also, Bandura saw consequences as regulators of future behavior. This helps an actor choose actions for obtaining a desired result based on information about possible future consequences. Bandura focused on the correction of antisocial behaviors through behavior modification. He felt this could be accomplished by manipulating the consequences of a child's behavior so that it is more rewarding to adopt acceptable behavior than to continue with unacceptable behaviors. This type of behavior modification was divided into four steps. They include identifying the specific behavior, arranging for the child to try out new behaviors, determine what consequences will be rewarded and which will be punished, and to manipulate the consequences so that desired behavior yields a greater reinforcement than the undesirable behavior. Social cognition theorists believe that this type of behavior modification is the most effective way to correct deviant behavior in children in a positive way.

\section{Limitations of the Study}

Since the value of qualitative research lies in the particular descriptions and themes developed in a context of specific sites, generalizations from these findings to other individuals, sites, or places outside of those under the study cannot be made. However, information derived from the findings in the study might be transferable to other similar kindergarten 
teachers or in settings that have the same type of philosophical beliefs. This study was limited to 20 public schools that have kindergarten classes in Irbid city of Jordan.

\section{Method}

This study used a descriptive qualitative design that utilized both an initial semistructured one-on-one interview containing open-ended questions with teachers, as well as observations of Jordanian kindergarten teachers. Data was gathered on the causes, types of aggression, and prevention strategies. Teachers were given the opportunity and freedom to express their individual views, which will help researchers reach a deeper understanding of their perspectives on the issue (Maxwell, 1992). Qualitative descriptive design is the method of choice when straightforward descriptions of phenomena are desired (Sandelowski, 2000).

\section{Setting and Participants}

Jordan is predominantly an Arab-Muslim country with a population of approximately 9 million, with about $35 \%$ under the age of 14 . Since Jordan is considered a poor country in terms of resources; children are considered valuable to the country. The country grows by the children growing in a healthy environment and becoming productive responsible adults.

Participants were found by "purposeful choice," which means that individuals and sites are selected for the study based on who can best help to understand occurrences for the topics to be investigated (Hatch, 2002; Merriam, 2002). In contrast to other sampling procedures in qualitative research, nothing is random or statistically representative about the sample since the intent is not to generalize to a population (Denzin \& Lincoln, 2005). A recruitment letter was sent to a participant population of convenience from Irbid district schools in Jordan, the first 20 teachers who responded were selected as participants.

The population was accessed through the head of the educational supervision department, which gave access to the principals of the desired schools. The principals of the schools then sent letters to teachers requesting access based on the plan and purpose of this study. The number of public schools that have kindergarten classes was limited in the urban city in the north of Jordan, which made the selection of kindergarten teachers easier.

Table 1

Demographics of Kindergarten Teachers

\begin{tabular}{llll}
\multicolumn{5}{c}{ Demographics of Kindergarten Teachers } \\
\hline \multicolumn{1}{c}{ Variable } & Variable levels & Count & $\%$ \\
\hline Teacher's & 2 years College & 0 & $0 \%$ \\
Qualification & BA degree & 19 & $95 \%$ \\
& Master and more & 1 & \\
Gender & & & $5 \%$ \\
& Male & 0 & $0 \%$ \\
Experience & Female & 20 & $100 \%$ \\
& less than 5 years & 2 & $10 \%$ \\
& 5 years to 10 & 6 & \\
& years & & $30 \%$ \\
& More than 10 & 12 & $60 \%$ \\
& years & & \\
& Total & 20 & $100 \%$ \\
\hline
\end{tabular}

Table 1 outlines the demographics of the participants in this study.

\section{Data Collection}

Data sources included classroom observations and teachers' interviews and follow-ups (member checks). All data was collected between September 4 and December 4, 2016. During this time, the researchers prepared all data for analysis. In order to collect the data several arrangements took place via telephone calls with principals and volunteer participants after the researcher had the principals' permission. Only those who consented to participation and contacted the researcher were considered for the study. The participants signed informed consent forms stating the method of data collection and specific procedures to collect the data, they were also asked to provide pseudonyms to protect their anonymity. The education department and gatekeepers' permissions were asked prior to contacting participants. The audio tapes were stored in a locked cabinet. All audio-taped interviews were destroyed one year after the study was completed.

The authors arranged to observe each kindergarten teacher. The observations took place twice on two different days for four hours each day for a total of 8 hours for each participant. The teacher explained the presence of the researcher to the children. Afterward, another arrangement took place for face to face interviews with the kindergarten teachers for one-hour interviews which were conducted by the second author and then were audio-taped.

The interview protocol had two icebreaker questions, which helped to transition the participant into the actual questions. There were 9 
questions that also included follow-up probing questions (see Appendix A). The probing questions were necessary as they allowed the researcher to elicit rich and thick information from the participants that they may not have considered to be relevant (Yin, 2009). The interview questions were built according to research's questions. Moreover, four faculty members in one university who are experienced in the field of early childhood education reviewed the interview questions and gave recommendations to improve the validity of the questions in relation to the research questions. The interviews took place at locations and times that were feasible for both the researcher and the participant. Moreover, the participants were asked to check their responses after the researcher transcribed their interviews and observation field notes.

\section{Data Analysis}

The interviews were transcribed from audio recordings, and observations were transcribed from field notes. Since the data were collected in Arabic, the transcripts were translated from Arabic into English. After translation, data were reduced into relevant and meaningful statements (Hatch, 2002) and were considered as themes. Then data were presented in a narrative form.

Thus, initially the researchers worked with the data, organized all of the pieces, broke them into manageable units, synthesized them, and searched for patterns, to discover what is important and what is to be learned (Bogdan \& Biklen, 1992). Furthermore, they worked out codes to identify pre-emergent or initial themes through bracketing the data (\& Lincoln, 2005). Finally, the researcher utilized NVivo 10 in order to help in arranging and organizing the codes and themes to determine whether any other themes were identified via electronic means.

The method of verification was inter-coder agreement. "Inter-coder reliability is a measure of agreement among multiple coders for how they apply codes to text data" (Kurasaki, 2000, p. 179). Each researcher independently coded her transcribed interviews and observation field note prior to collaborating as a team to identify common categories. Then, the researchers selected one transcript to begin the coding process and collaborated to reach an inter-rater reliability of 90\%. Cohen (1960) suggested that 80 percent inter-coder agreement would be considered a good predictor of reliability of the research.

\section{Establishing Credibility}

In qualitative research, one or more types of validation procedures are used to ensure accuracy of the data. Validation may be accomplished through the use of member checking and triangulating sources of data (Denzin \& Lincoln, 2005). To ensure the credibility of this study, the researchers utilized five verification procedures including: (a) triangulation (Lincoln \& Guba, 1985; Yin, 2009), (b) member checking (Lincoln \& Guba, 1985), (c) peer review (Merriam, 2009), (d) external auditor (Hatch, 2002), and (e) thick rich description (Geertz, 1973, 1983).

\section{Research Findings}

Based on the analysis of all data sources including interviews and observations, three major themes regarding appropriate prevention strategies of aggression in Jordanian kindergarten emerged.

Theme 1: Factors shape aggression. Based on data analyses, several factors toward aggression were identified by kindergarten teachers. These included: (a) modeling of aggressive behavior from TV, movies, family members, and games; (b) peer conflict; (c) family conflict and maltreatment; (d) cultural values and traditions; and (e) harsh physical punishment from parents. Interestingly, 15 of the 20 participants stated that cultural values and traditions were a major cause of children's aggressive behavior. They stated that "Some parents believed that the best way for dealing with children is by punishment, in this way the kids learn very quickly." Teachers stated that some children faced harsh physical punishment from their parents, such as Teacher C, who said, "One of my students came to the school with blue and red around his eye, he was hit by his dad because of misbehaved." Teacher K also stated, "A little girl in her class showed her hand with a big bite from her mom." Instead of modeling these aggressive behaviors, the participants stated that social learning through positive modeling could help change aggressive behaviors. 
Classrooms' observations matched the literature in several ways. All of the participants discussed two types of aggression emerging in preschool, which were relational and physical aggression. Moreover, the researcher noted boys were more physically aggressive while the girls were more relationally aggressive.

Theme 2: Sanctions rather than punishment. "It is important for children to think about their actions," Teacher A said. In doing so, most of these teachers said they used sanctions rather than rewards or punishments. Teacher F stated, "I hate to punish children; using punishment would rather increase the aggressive behavior among children." Data shows that participants used sanctions that required the child to be an active participant in accepting responsibility for his or her own behavior. Teacher F added, "Punishments are administered from a source outside the child such as a teacher or parent instead."

One example of a sanction based on class observations came from Teacher G, who temporarily timed out a child from the group until he could regain self-regulation. The child decided when to return to the group and act responsibly. She directed the child's attention to the consequences of his actions. And then, the boy soon apologized for his inconsiderate actions. Teacher G said these actions "would help children to rethink in their actions and the corresponding consequences". Another example came from Teacher $\mathrm{M}$, who required the child to make restitution by asking children to pay money for breaking or abusing property, fix damaged property, or clean up a mess they have made instead of punishment. She said, "In some situations I asked children to pay money for breaking or abusing property, fix damaged property, clean up a mess, for examples, and that depended on what the children did."

Theme 3: Social learning and culture. Teachers expressed that social learning could take place through: (1) modeling the desired behaviors, (2) children's literature like songs and stories, (3) using drawing as a teaching strategy, (4) role-plays, (5) treating children with empathy and respect, and (6) using treatments embraced by Islam.

Teacher D stated, "Aggressive students are in need of social learning, they need to learn the appropriate way to deal with different situa- tions, so I use many strategies such as reading stories which show different situations to teach kind and respectful manners." Other teachers used kid's songs to get children's attention on appropriate and inappropriate behaviors. For example, Teacher S said, "We sing a song that portrays both appropriate and inappropriate behavior; I used it as a vehicle for discussing positive ways for handling aggression." Some teachers also used role-plays to help the children develop compassion and empathy for him or herself as well as the "victim." Teacher N said, "Role-playing helps children practice what to do instead of acting out aggressively."

Furthermore, it is vital to treat children with empathy and respect, which was obvious from the class observations. Teacher A said, "Treating children with empathy teaches them to treat others in the same way." Also, Teacher F stated, "I always let children know that you care about them, trust and respect them". She reminded the child with the aggressive behavior nicely that it's the inappropriate behaviors that I don't like and other children do not like too. These teachers also tried to get children to feel they are all as a family so they have to deal with other students as sisters and brothers at the classroom. Teacher D said, "I always remind them they are a family and I like them to work together reminding that they all are like sisters and brothers."

It is important for teachers to understand the reasons behind aggressive behavior. These teachers utilized several different tools to do so. Some teachers used drawing for both finding out why children were being aggressive, and as a treatment to help the child develop and express their feelings. Teacher J said:

Letting children draw freely helped me a lot. One time I discovered that the step-mother of one of my students hit the student's sister at the sea, and that was why he was afraid of the sea and did not accept to draw the sea at the beginning. Some family conflict, children cannot talk about it, but we can find it through children drawing.

Teacher M added, "Some children draw his or her father or mother with ugly and angry faces, and that means how their family deals with them." Teachers also tried to understand the feeling behind the behaviors. Teacher $\mathrm{C}$ said, "It is important to children to give them the 
adequate time to express themselves verbally." Teachers also helped the children find the tools to manage anger, frustration, and disappointment more appropriately. These tools included feeling vocabulary and pictures, which helped children talk about rather than act out angry feelings. Through the observation of the morning circle, all the participants discussed the feeling tools, which are pictures that show various feelings, such as anger, happiness, sadness, etc., and then they discussed these feelings with the children and gave the children the time to talk about their feeling and choose the picture that fit with the feeling.

Also, twelve participants' used treatments embraced by Islam. The class observations revealed that teachers reminded the kids with chapters from the Quran and explained how good people were expected to act. Also, Teacher $Q$ said:

I always recall some chapters from the Quran and Hadith from Prophet Mouhammed's legacy, which urges children on the importance of group work as we are one family and children are brothers and sisters on this basis. For instance, (None of you truly believes until he loves for his brother what he loves for himself.) (The believers are like one person; if his head aches, the whole body aches with fever and sleeplessness.). (Sahih Bukhari)

Also, teacher H said:

"Children in my classroom are team members. I have been working on this value since the beginning of the year. I devoted more emphasis of the activities that support children working together as caring friends not competitors. I consistently remind them that "the hand of Allah is with the group."

In addition to the three themes that were found, the teachers recommended implementing several other constructive measures that could reduce aggression and nurture positive teacher-student relationships by which students are empowered to learn and grow. One recommendation was to reduce class size and increase administrative support. The participants also recommended a good and positive relationship with the family. These teachers sent daily folders with notes to each child's home and shared their email addresses and telephone numbers with the parents or fami- lies so that teachers were easy to contact. These teachers also sent pictures of children engaged in activities to the families and met with families for conferences. For example, Teacher G said:

I send notes home. That's my primary form of communication. I do phone calls, as well. And, when I call home, it's not necessarily a bad thing. I might say, "Your child has had a great day together" with a smiley face. But, unfortunately, when I asked for a conference or meeting with a family, most of them do not come, because they are afraid that their child is engaged in problems.

\section{Discussion}

This investigation brings together two important areas to the study of development and advances our knowledge in a relatively understudied area of research, aggression behaviors and teachers' intervention programing. The following discussion reports the major findings related to each research question and mirrors the reviewed literature.

Why do children become aggressive? Data analysis revealed kindergarten teachers identified several factors toward aggression. These included: (a) modeling of aggressive behavior from TV, movies, family members, and games; (b) family conflict and maltreatment; (c) peer conflict; (d) cultural values and traditions; and (e) harsh physical punishment from parents.

When children watch aggressive actions on TV for a long time, it is normal to imitate these actions and use it with their peers or parents. This finding is consistent with Daly and Perez (2009), who stated that media violence increased probabilities of aggression. Gentile, Coyne, and Walsh's (2011) study indicated consumption of media violence was associated with higher verbally and physically aggressive behaviors along with lower prosocial behaviors. As a result, watching media violence is associated with aggressive behavior in kindergarten children.

Also, children who had violence or aggression in their home were said to be imitating their parents. This result is consistent with Cullerton-Sen et al., (2008), Ben Haleam (2014), and Abu Alrub, Rababeah, and Mustafa (2017). As expected, maltreated children exhibited higher 
levels of aggression than non-maltreated children.

Moreover, Powers and Bierman's (2012) study revealed that students sitting near aggressive peers showed an increased likelihood of gaining aggression by modeling their behavior. This result stems from children mirroring what they have seen or experienced.

What are the types of aggression that emerge in Jordanian kindergartens? According to data from the teachers' interviews and classroom observations, the two common types of aggression that emerge in Jordanian kindergartens were grouped into relational and physical aggressions. Boys were more physically aggressive, while girls were more relationally aggressive. This finding supported previous research findings (McEvoy et al., 2003; Ostrov \& Crick, 2007; Ostrov et al., 2008; Tremblay et al., 2004), which all found that males had a higher rate of physical aggression than females, while girls had higher rates of relational aggression. Girls at this age frequently do not express their feelings when they are angry. Therefore, relational aggression may be a covert or indirect way in which the aggressor does not directly address the victim. However, boys at this age frequently used their body and hands to express their feelings when they are angry, often as physical aggression.

How do pre-school teachers handle aggressive behavior in Jordanian kindergartens? The kindergarten teachers used different procedures to address and treat children's aggressive behavior. The most successful procedures used to deal and treat children's aggressive behavior were the use of sanctions rather punishment, which incorporates the child with the consequences of their actions. Social learning was another important procedure, which could take place through: (1) modeling desired behaviors, (2) children's literature like songs and stories, (3) using drawing as a teaching strategy, (4) role-plays, (5) treating children with empathy and respect, and (6) using treatments embraced by Islam. These findings fit well with Bandura's (1977) social learning theory that people learn through modeling and observational learning. Teachers suggested class time should be devoted to teaching students prosocial behavior, such as getting along with others and showing respect for each other and the teachers.
Teachers stated that learning model behavior through storytelling and plays was a major benefit to students. Along these lines, many stories have been specifically written to help children develop socially approved behaviors and values in improving social and friendship skills in young children (Zhang, 2011). Moreover, Gregory and Weinstein (2008) suggested that a fun, prosocial learning tool in behavioral learning for students could be games.

Social learning could be the bridge that connects appropriate behaviors and reactions to the classroom setting for students who do not have these models at home. Helterbran (2009) argued that schools should actively plan to teach moral development starting at the elementary level in order to avoid leaving character education to chance. Children learn disruptive aggressive behaviors (opposition, defiance, rule-breaking, stealing) from their environment (Works, 2015); if this is true, then they can also learn positive behaviors from positive social learning in the classroom on a daily basis (Fung \& Tsang, 2007; Works, 2015). Leffert, Brady and Siperstein (2009) suggested that teachers could infuse daily social skills into the curriculum with a 20-minute lesson focused on enhancing peer relations through understanding feelings and the feelings of others, anger management strategies, problem solving techniques, and appropriate behavior at school. For students who exhibit emotional and behavioral disorders, social learning is as important as the academic curriculum (Regan, 2009; Works, 2015).

These findings indicate that good socializations need to be stressed in preschool curriculum. Sharing, caring, compassion, patience, selflessness and tolerance, are all ethics to be developed through group work and collaboration. In the context of Jordan, children primarily belong to Muslim communities, so these ethics can be taught through Islamic morals. Reducing disruptive behaviors can be accomplished by doing as many of the following as possible. Teachers could be provided with professional training in aggression; implement zero tolerance of aggressive, harmful acts; and administrators could also help by reducing classroom sizes. Research has shown that a proper class size is essential in reducing the achievement gap (Burch, Theoharis, \& Rauscher, 2010; Tienkan \& Achilles, 2009); but too many aggressive students in one class- 
room can increase levels of classroom aggression (Thomas, Bierman, \& Powers, 2011). Therefore, an ideal classroom size seems to be in the middle, not too big or too small.

Lastly, counselors and administrators should work together and provide significant ways of supporting teachers on a regular basis, such as specific intervention programs. Previous research has shown that school counseling interventions are critical in helping aggressive students adjust to school (Whiston, Tai, Rahardja, \& Eder, 2011). Other research found intervention programs to have an effect over time for reducing physical aggression behavior in at risk children (Brotman et al., 2008).

\section{Conclusion and Recommendations}

This study sought to explore and understand the types and causes of aggression, as well as ways that teachers use to treat and react to aggressive children in Jordanian kindergartens. Data sources included classroom observations and teacher interviews. Understanding concrete ways that teachers were positively treating and reacting to aggression in their classroom was the most important finding of this study. The practices of teachers provided in this study focused on issues related to discipline, gender roles, and the roles of parents and teachers. The results indicated that social learning, through positive modeling, was most needed to help aggressive and disruptive students change their behavior. Students can be less aggressive by learning how to communicate instead of fighting. The teachers' actions to prevent aggressive and disruptive behaviors connected closely with the study's conceptual framework of behavioral learning and social learning theory.

Additional teacher recommendations included professional training on social learning strategies, reducing class size, increasing administrative support, and providing social learning programs for aggressive students. These recommendations could lead to social change by implementing constructive measures to reduce aggression and nurture positive teacherstudent relationships by which students are empowered to learn and grow.

The problems examined in this study are both important and complex; therefore, more studies on this topic are highly recommended to achieve broader understanding of the phe- nomena. Further studies are needed to explore what teachers do and how they achieve teaching principles of their social, cultural, and religious beliefs. The findings of this study also further support the importance of counseling interventions. Along these lines, the effectiveness of various intervention techniques could be examined further.

\section{References}

Abu Al Rub, M.F., Rababaeh, E.Q. \& Mustafa, I.G. (2017). Maternal socialization and kindergarten children's behaviors from Jordanian mothers' and teachers' perspectives. Early Childhood Education Journal, 45(2), 271-283.

Al Saleh, T. (2012). The Degree of aspects and causes of the aggressive behavior among basic grade student at the elementary classes in northern governmental schools in the Northern Governorates West Bank and the methods of treatment from the teachers' view point. Unpublished Master Thiess, An-Najah National University.

Aldridge, J. \& Goldman, R. (2007). Current issues and trends in education (2nd ed.). Boston, MA: Allyn and Bacon.

Al-Sarayreh, K. (2009). Reasons leading to student's violence against teachers and administrators in Jordanian Public Secondary Schools from the viewpoint of students, teachers and administrators. Jordanian Article of Educational Science, 5(2), 137157.

Arbeau, A. K., \& Coplan, J.R. (2007). Kindergarten teachers' beliefs and responses to hypothetical prosocial, asocial, and antisocial children. Merrill-Palmer Quarterly, 53(2), 291-316.

Bandura, A. (1977). Social learning theory. Englewood Cliffs, NJ: Prentice-Hall.

behavioral disorders. Teaching Exceptional Children, 41(5), 60-65

Ben Haleam, A. (2014). The relationship between children' aggressive behavior and children' neglected by their mothers. Journal of Social Studies and Researches, 7, 21-37.

Bogdan, R. C., \& Biklen, S. K. (1992). Qualitative research for education: An introduction to 
theory and methods. Boston: Allyn and Bacon.

Brotman, L. M., Gouley, K. K., Huang, K. Y., Rosenfelt, A., Neal, C. O., Klein, R. G., \& Shrout, P. (2008). Preventive intervention for preschoolers at high risk for antisocial behaviour: Long- term effects on child physical aggression and parenting practices. Journal of Clinical of Child $\mathcal{E}$ Adolescent Psychology, 37(2), 386-396.

Center of Excellence Early childhood Development. (2008). Eyes on aggressive behaviors. From:

childhood: A short term longitudinal study. School Psychology Review, 36(1), 2243

Cohen, J. (1960). A coefficient of agreement for nominal scales. Educational and Psychological Measurement, 20, 37-48.

Connor, S. (2007). Nature not nurture is to blame for aggressive children. From:

Cote, S. M., Boivin, M., Nagin, D. S., Japel, C., $\mathrm{Xu}, \mathrm{Q} ., Z^{2}$ Zoccolillo, M., ... Tremblay, R. E. (2007). The role of malternal education and nonmaternal care services in the prevention of children's physical aggression problems. Arch Gen Psychiatry, 65(11), 1305-1312.

Cullerton-Sen, C., Cassidy, A. R., MurryClose., Cicchetti, D., Crick, N. R., \& Rogosch, F. A. (2008). Childhood maltreatment and the development of relational and physical aggression: The importance of a gender-informed approach. Child Development, 79( 6), 1736- 1751.

Daly, L. A., \& Perez, L. M. (2009). Exposure to media violence and other correlates of aggression behavior in preschool children. Early Childhood Research \& Practice (ECRP), 11(2). From:

Denzin, N. K., \& Lincoln, Y. S. (Eds.). (2005). The sage handbook of qualitative research ( $3^{\text {rd }}$ ed.). Thousand Oaks, CA: Sage.

Doumen, S., Verschueren, K., Buyse, E., Germeijs, V., \& Luyckx, K. ( 2008). Reciprocal relations between teacher-child conflict and aggressive behavior in kindergarten: A three-wave longitudinal study. Journal of Clinical Child \& Adolescent Psychology, 37(3), 588-599.
Dykeman, B. F. (2003). The effect of family conflict resolution on children's classroom behavior. Journal of Instructional Psychology, 30(1), 41-46.

Fung, A. L. C., \& Tsang, S. K. M. (2007). Anger coping method and skill training for Chinese children with physically aggressive behaviors. Early Child Development and Care, 177(3), 259-273.

Geertz, C. (1983). Local knowledge: Further essays in interpretive anthropology. New York: Basic Books.

Geertz, C. (1973). The interpretation of cultures: Selected essays. New York: Basic Books.

Gentile, D. A., Coyne, S., \& Walsh, D. A.(2011). Media violence, physical aggression, and relational aggression in school age children: A short-term longitudinal study. Aggressive Behavior, 37(2), 193-206.

Hatch, J. (2002). Doing qualitative research in educational settings. Albany, New York: State University of New York Press.

Helterbran, V. R. (2009). Linking character education and global understanding through children's picture books. Kappa Delta Pi Record, 45(2), 69-73.

http://ecrp.uiuc.edu/v11n2/daly.html

http://scholarworks.waldenu.edu/cgi/vi ewcon-

tent.cgi?article $=1191 \&$ context $=$ dissertation

Kurasaki, K. S. (2000). Intercoder reliability for validating conclusions drawn from openended interview data. Field Methods, 12(13), 179-194.

Leffert, J. S., Brady, M. E., \& Siperstein, G. N. (2009). A "Tools for Teachers" approach for infusing social skills instruction into daily teaching activities. Teaching Exceptional Children Plus, 6(2). 1-23.

Lincoln, Y. S., \& Guba, E. G. (1985). Naturalistic inquiry. Beverly Hills, CA: Sage.

Manning, M. A., \& Bear, G. G. (2002). Are children's concerns about punishment related to their aggression? Journal of School Psychology,40(6), 523-539.

Maxwell, J.A. (1992). Understanding and validity in qualitative research. Harvard Educational Review, 62(3), 279-301.

McComas, J. J., Johnson, L., \& Symons, F. J. (2005). Teacher and peer responsivity to 
pro-social behaviour of high aggressors in preschool. Educational Psychology, 25(2-3), 223-231.

McEvoy, M. A., Estrem, T. L., Rodriguez, M. C., \& Olson, M. L. (2003). Assessing Relational and physical aggression among preschool children: Intermethod agreement. Topic in Early Childhood Special Educatin, 23(2), 53-63.

Merriam, S. B. (2002). Assessing and evaluating qualitative research. In S. B. Merriam (Ed.), Qualitative research in practice (pp. 18-39). San Francisco, CA: Jossey-Bass Publishers.

Merriam, S. B. (2009). Qualitative research: A guide to design and implementation. San Francisco, CA: Jossey-Bass.

Ostrov, J. M., \& Crick, N. R. (2007). Forms and functions of aggression during early

Ostrov, J. M., Massetti, G. M., Stauffacher, K., Godleski, S. A., Hart, K. C., Karch, K. M.,. . . Ries, E. E. (2009). An intervention for relational and physical aggression in early childhood: A preliminary study. Early Childhood Research Quarterly, 24, 15-28.

Ostrov, J. M., Ries, E. E., Stauffacher, K., Godleski, S. A., \& Mullins, A. D. (2008). Relational Aggression, physical aggression and deception during early childhood: A multimethod, multi-informant short-term longitudinal study. Journal of Clinical Child $\mathcal{E}$ Adolescent Psychology, 37(3), 664-675..

Posada, G., Pratt, D. M. (2008). Physical aggression in the family and reschoolers' use of the mother as a secure base. Journal of Marital and Family Therapy, 34(1), 14-27.

Powers, C. J., Bierman, K. L. (2012). The multifaceted impact of peer relations on aggressive-disruptive behavior in early elementary school. Developmental Psychology. 49(6):1174-1186

Raaijmentz ,M. A. J., Smidts, D. P., Sergant, J.A., Maassen, G. H., Posthumus. J. A., England, H. V., \& Matthys, W. (2008). Executive function in preschool children with aggressive behavior: Impairment in Inhibitory control. Journal of Abnormal Child Psychology, 36, 1097-1107.
Regan, K. S. (2009). Improving the way we think about students with emotional and/or

Sakimura, J. N., Dang, M. T., Ballard, K. B., \& Hansen, R. L. (2008). Cognitive and temperament clusters in 3-to 5-year-old children with aggressive behavior. Journal of School Health, 78, 38-45.

Sandelowski, M. (2000), Combining Qualitative and Quantitative Sampling, Data Collection, and Analysis Techniques in Mixed-Method Studies. Nurs. Health, 23246-255.

Shaffer, D. R. (2009). Social and personality development (6th ed.) Belmont, CA: Wadsworth.

Shechtman, Z., \& Ifargan, M. (2009). Schoolbased integrated and segregated interventions to reduce aggression. Aggressive Behavior, 35, 342-356.

Thomas, D. E., Bierman, K. L., \& Powers, C. J.(2011). The influence of classroom aggression and classroom climate on aggressive-disruptive behavior. Child Development, 82(3), 751-757.

Thomas, R. M. (2005). Comparing theories of child development (6 $6^{\text {th }}$ ed.). Belmont, CA: Wadsworth Pub. Co.

Thornberg, R. (2006). The situated nature of preschool children's conflict strategies. Educational Psychology, 26(1), 109-126.

Tremblay, R. E., Nagin, D. S., Seguin, J. N., Zocolillo, M., Zelazo, P. D., Boivin, M., . . . Japel, C. ( 2004). Physical aggression during early childhood: Trajectories and predictors. American Academy of Pediatrics, 114(1), 42-50.

Waliski, A. D., \& Carlson, L. A. ( 2008). Group work with preschool children : Effect on emotional Awareness and behavior. The Journal for Specialists in Work, 33(1), 3-21.

Whiston, S. C., Tai, W. L., Rahardja, D. and Eder, K. (2011), School counseling outcome: A Meta-Analytic examination of interventions. Journal of Counseling $\mathcal{E}$ Development, 89, 37-55.

Works, D.M (2015). Teachers' experiences concerning the rise in student aggression. Doctoral Thesis presented to Walden University. From: 
www.excellence-earlychildhood.com www.independent.co.uk

Yin, R. K. (2009). Case study research: Design and methods. (4th ed.) Thousand Oaks, CA: Sage Publications

Zhang, K. C. (2011). Let's have fun! Teaching social skills through stories, Telecommunications and activities. International Journal of Special Education, 26 (2). 70-78. 